\title{
Using Qualified On-Site Nuclear Power Plant Simulators in Human Factors Validations of Control Room Upgrades
}

\section{February 2021}

Jeffrey C Joe, Casey R Kovesdi

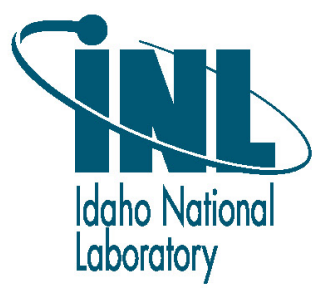




\section{DISCLAIMER}

This information was prepared as an account of work sponsored by an agency of the U.S. Government. Neither the U.S. Government nor any agency thereof, nor any of their employees, makes any warranty, expressed or implied, or assumes any legal liability or responsibility for the accuracy, completeness, or usefulness, of any information, apparatus, product, or process disclosed, or represents that its use would not infringe privately owned rights. References herein to any specific commercial product, process, or service by trade name, trade mark, manufacturer, or otherwise, does not necessarily constitute or imply its endorsement, recommendation, or favoring by the U.S. Government or any agency thereof. The views and opinions of authors expressed herein do not necessarily state or reflect those of the U.S. Government or any agency thereof. 


\section{Using Qualified On-Site Nuclear Power Plant Simulators in Human Factors Validations of Control Room Upgrades}

Jeffrey C Joe, Casey R Kovesdi

February 2021

Idaho National Laboratory

Idaho Falls, Idaho 83415

http://www.inl.gov

Prepared for the U.S. Department of Energy Under DOE Idaho Operations Office

Contract DE-AC07-05ID14517 


\title{
Using Qualified On-Site Nuclear Power Plant Simulators in Human Factors Validations of Control Room Upgrades
}

\author{
Jeffrey C. Joe ${ }^{1, *}$, Casey Kovesdi ${ }^{1}$ \\ 1 Idaho National Laboratory, Idaho Falls, Idaho, USA \\ \{Jeffrey.Joe, Casey.Kovesdi\}@inl.gov
}

\begin{abstract}
Existing commercial nuclear power plants (NPPs) are valuable assets in the infrastructure portfolio of the United States because they safely and reliably generate about $1 / 5^{\text {th }}$ of all the electricity used. The instrumentation and control $(I \& C)$ systems in commercial NPPs are the 'eyes and ears' of the operator, allowing operators to maintain situation awareness, thereby allowing the plant to operate safely and efficiently for all phases of operation. Because the I\&C systems in NPPs are still mostly based on analog technologies, which are reliable but not especially cost-effective, upgrading the existing I\&C in commercial NPPs to new digital $I \& C$ is very important. Furthermore, simulators and simulation are critical human factors engineering tools for this $I \& C$ modernization work. NPP control room simulators are essential test beds to simulate normal, abnormal, and emergency operations that allow human factors researchers to safely and realistically evaluate early design phase prototypes of the upgraded digital $I \& C$ and validate final as-built digital I\&C systems that have been modernized and deployed in NPPs. This paper describes research performed using qualified on-site NPP simulators to perform human factors validations of digital $I \& C$ control room upgrades.
\end{abstract}

Keywords: Human factors engineering $\cdot$ Simulators $\cdot$ Simulation $\cdot$ Nuclear power plant modernization

* Corresponding author: Tel.: +1-208-526-4297·E-mail address: Jeffrey.Joe@inl.gov 


\section{Introduction}

In January 2021, the United States (U.S.) Department of Energy (DOE) Office of Nuclear Energy (NE) published their strategic vision [1]. DOE-NE's strategic vision includes five goals, with supporting objectives to address "challenges in the nuclear energy sector, help realize the potential of advanced technology, and leverage the unique role of the government in spurring innovation" (pg. 3). As seen in Figure 1, the first goal is to enable the continued operation of existing commercial nuclear power plants (NPPs) by conducting research and development $(R \& D)$ to create technologies that reduce operating costs and expand nuclear energy beyond the electricity market.

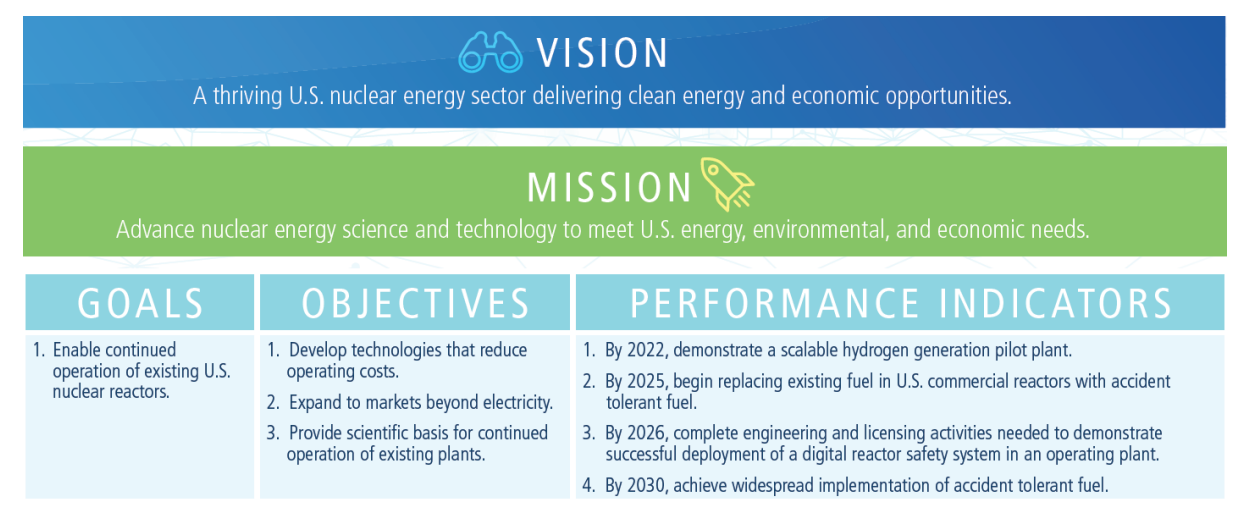

Fig. 1. Vision, Mission, Goals, Objectives, and Performance Indicators from the U.S. DOE-NE 2021 Strategic Vision. [1]

In support of this goal, DOE-NE has been sponsoring the Light Water Reactor Sustainability (LWRS) Program, which facilitates R\&D performed in collaboration with utilities to enable the continued operation of existing commercial NPPs. The LWRS Program's scope includes human factors R\&D and human factors engineering (HFE) to support plant modernization and, in particular, the digital transformation of legacy control room instrumentation and control (I\&C) systems.

I\&C systems in commercial NPPs are the 'eyes and ears' of the operator, allowing operators to maintain situation awareness, thereby allowing the plant to operate safely and efficiently for all phases of operation. The I\&C systems in U.S. commercial NPPs are still mostly based on analog technologies, which are reliable but not especially cost-effective. Upgrading the existing I\&C systems in commercial NPPs to more cost-effective digital $I \& C$ is thus a primary way to 
achieve the goal of continued operations of existing U.S. nuclear reactors.

\subsection{Nuclear Power Plant Simulators and Simulation}

NPP simulators and simulation are critical HFE tools for this I\&C modernization work. NPP control room simulators are essential test beds to simulate normal, abnormal, and emergency operations that allow human factors researchers to safely and realistically evaluate early design phase prototypes of the upgraded digital I\&C and validate final as-built digital I\&C systems that have been modernized and deployed in NPPs.

The simulators and simulation used in the nuclear industry can vary significantly in their size and complexity. While others have provided a more complete and thorough treatment of simulators used in human factors [3], for the purposes of this paper, a simplified categorization scheme to delineate the types of simulators used in the nuclear industry is provided here. At one end of the spectrum are part-task simulators, which are sometimes referred to as microworlds. Microworlds are a simplified representation of the system being simulated, which often means that nonexperts of that system can be trained and used as participants in controlled experiments [4].

Somewhere in the middle, but near the higher end of the spectrum, is the Human System Simulation Laboratory (HSSL) at Idaho National Laboratory (INL). INL's HSSL, as seen in Figure 2, is a full-scope, full-scale NPP control room simulator. The HSSL simulator uses the same software that is run on the on-site simulators at NPP that are used to train, qualify, and license NPP operators. As such, the HSSL simulator model includes all functions found in a control room and is capable of modeling normal, abnormal, and emergency plant operations. In addition, the HSSL is reconfigurable, such that it can mimic multiple control room layouts and simulate both analog and digital I\&C systems.

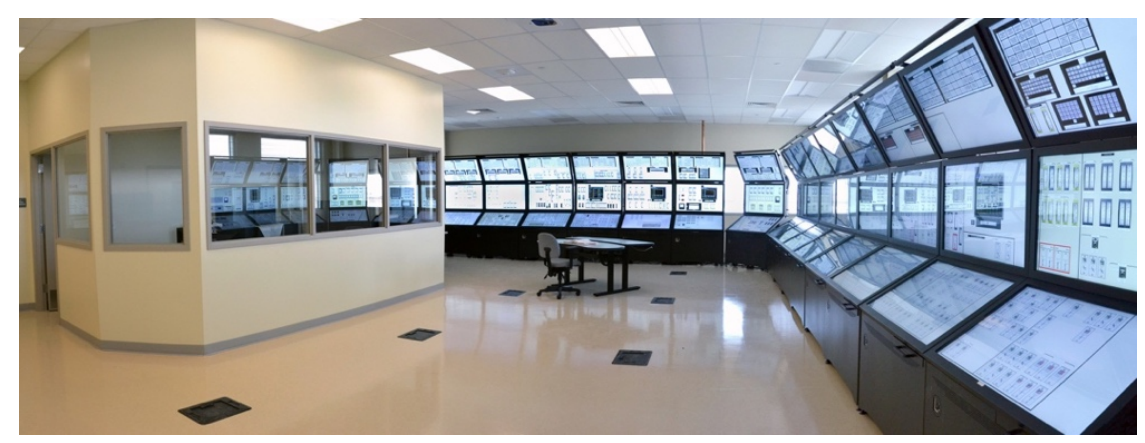


Fig. 2. The Human System Simulation Laboratory at Idaho National Laboratory.

At the top end of the spectrum are the qualified, on-site training simulators. These simulators are as close to the actual main control room (MCR) as is possible, using the same hardware and control systems that are in the MCR. Qualified on-site simulators are required to meet rigorous standards for simulator fidelity, as specified in [5], which establishes, "The functional requirements for full-scope nuclear power plant control room simulators for use in operator training and examination, as well as criteria for the scope of simulation, performance, and functional capabilities of simulators." (pg. 4) [6] The consensus standard [5] also includes information on, "Simulator scenario-based performance testing, new sections addressing simulator core performance testing and post-event simulator testing, and other important guidance required to ensure accurate simulation for use in operator training and examination" (pg. 4) [6]. It is because on-site training simulators meet these rigorous standards that they are assured to be very high fidelity.

There are a number of trade-offs with respect to the advantages and disadvantages of using microworlds, the HSSL, or qualified on-site simulators in human factors R\&D. As mentioned previously, microworlds are simplified, lowfidelity simulations of the system, which allow experimental human factors researchers to use large pools of participants who are not licensed operators. This allows the researchers to collect large amounts of data for use in inferential statistical tests at a relatively low cost. Attempting to collect the same amount of data from licensed NPP operators on their qualified on-site simulator would be prohibitively time-consuming and expensive, but, if high simulator fidelity is an important consideration in the research being conducted (e.g., integrated system validations), there is no better option than the qualified on-site simulator ${ }^{2}$. This paper describes research performed using qualified on-site NPP simulators to perform human factors validations of digital I\&C control room upgrades.

\section{Using the On-Site Simulator for Human Factors R\&D}

This research project involved conducting human factors operator-in-the-loop studies using the utility's qualified on-site control room simulators. The purpose of the studies was to conduct HFE validation assessments of the planned

\footnotetext{
${ }^{2}$ The HSSL is an excellent simulation tool because its flexibility allows human factors researchers to collect larger samples of data using a simulator that has at level of fidelity that is very close to the qualified on-site simulator.
} 
control room I\&C upgrades for four NPP units and had the objective of identifying potential HFE issues with the upgrades prior to installation in the MCR.

One unique aspect of this research was the availability of two different qualified on-site control room simulators. One on-site simulator had been upgraded with the new digital $I \& C$, and the second was at an identical NPP located a few hours away and had not been upgraded. This was a very rare opportunity to conduct comparative operator-in-the-loop research because not all commercial NPPs are alike with respect to the exact layout and design of their control rooms. In this case, however, the I\&C upgrades were occurring at two different NPP stations that were built at nearly the same time and had virtually identical control rooms. The fact that this study was conducted right in the time window where one simulator had been upgraded and the other had not adds to the true uniqueness of the opportunity.

The operator-in-the-loop studies entailed direct observations and assessments of key operator interactions with the existing and new human system interfaces (HSIs) across a number of normal, abnormal, and emergency scenarios. The scenarios were designed to evaluate the functional ergonomic and human factors aspects of the existing and upgraded I\&C systems, with a particular emphasis on the ability of the new I\&C system to support operators' cognitive processes and their ability to facilitate the operators' ability to per-

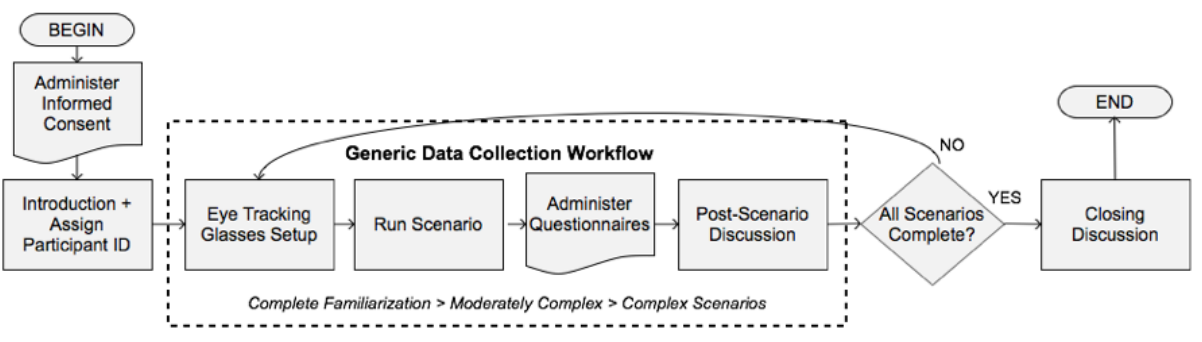

form the correct control actions. The general workshop flow is depicted in Figure 3.

Fig. 3. Workshop execution workflow.

The assessment strategy focused on assessing plant safety and overall human-system performance. As such, measures of usability, workload, and situation awareness $(\mathrm{SA})$ were collected during select scenarios to evaluate the suitability of the new HSls in an operational context. During each scenario, the evaluation team also identified key information that determined the success or failure of the new HSIs as installed. 
Human factors researchers and operationally experienced monitors observed the operators who performed actions in the scenarios using relevant procedures (see Figure 4). Observations focused on operator interactions that were affected by the upgraded controls and indicators. Changes in time available for operator action, as well as information availability, were identified by observers during the scenarios.
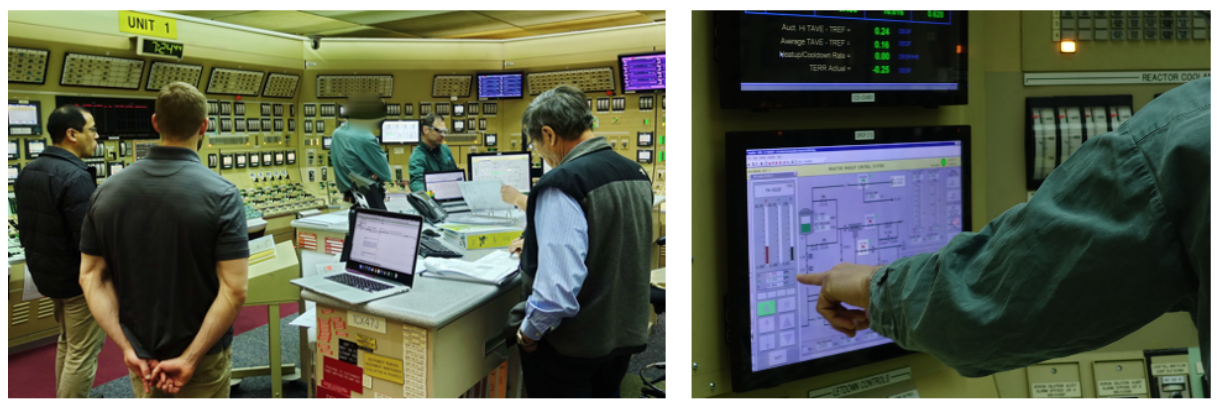

Fig. 4. Human factors researchers observing NPP operators interacting with the new HSI.

In addition to collecting performance data, a comparison between the existing and upgraded configurations was achieved by collecting self-report measures of perceived usability, workload, and SA. Specifically, the single ease question [7], National Aeronautics and Space Administration Task Load Index [8], and Situation Awareness Rating Technique [9] were used to collect selfreport measures of usability, workload, and SA, respectively. These questionnaires were provided to operators together after each scenario and operators were asked to complete each questionnaire independently. The ratings for each questionnaire type were aggregated across crew members for each scenario using the arithmetic mean to compare existing and upgraded configurations.

Notably, the extent to which perceived usability, workload, and SA were practically equivalent across the two configurations was of interest to the research team. That is, the extent to which any of the observed differences in ratings across these questionnaires had any meaningful difference, potentially reflecting a change in usability, workload, or SA, when introduced to the new upgrades, was evaluated through a series of two one-sided tests (TOSTs). TOSTs provide a means of testing statistical equivalence by setting up explicit composite null hypotheses based on creation of an upper $\left(\Delta_{U}\right)$ and lower $\left(-\Delta_{L}\right)$ equivalence bound. The logic of TOST is highlighted below: 
TOST provides a more accurate way of testing equivalence, as opposed to accepting the null hypothesis from a traditional two-sided statistical test of differences [10]. As such, rather than concluding equivalence by the absence of an observed effect, TOST requires more specific predictions of potential differences by comparing it to explicit equivalence bounds (i.e., $-\Delta_{\mathrm{L}}$ and $\Delta_{U}$ ).

This study set equivalence bounds for each questionnaire as two units of measurement. Since there were different operators used for the existing and upgraded configurations, the tests were set up as unpaired and assumed unequal variance. Type I error rates were set up as $\alpha=.20$ given the exploratory nature of these tests.

\section{Workshop Results}

Across each of the scenarios run for the two conditions, the human factors researchers and operationally experienced monitors observed no safety critical errors and no meaningful differences in completion times that were time critical in nature when introducing the new HSIs in the upgraded configuration. The TOSTs indicated statistical equivalence across perceived usability (ease of completion), workload, and SA. Figure 5 presents the results from these questionnaires. 


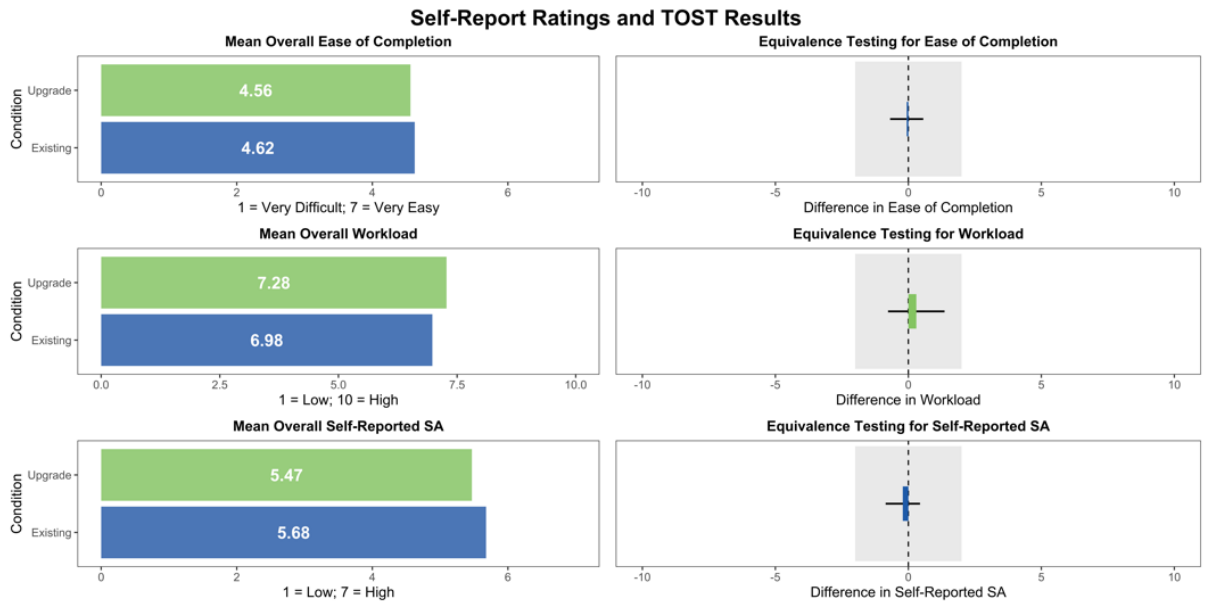

Fig. 5. Mean self-report ratings and TOST results for usability, workload, and SA.

In Figure 5, each row represents perceived usability (ease of completion), workload, and SA. On the left side, the colored bar charts illustrate the mean ratings for each questionnaire by condition (upgraded HSIs in green versus existing HSIs in blue). On the right side, TOST results are illustrated; the gray band indicates the region of practical equivalence as defined by $-\Delta_{\mathrm{L}}$ and $\Delta_{U}$ bounds. Where the upgraded HSI ratings were greater than existing HSIs, the difference is illustrated by a green bar in the positive direction. Where the existing HSIs configuration ratings were greater than the new HSI configuration, a blue bar is shown in the negative direction. There are $80 \%$ confidence intervals presented to illustrate whether the difference was practically equivalent; the intervals were all within the equivalence bound (gray region), indicating statistical equivalence. These results were further supported by the observation of no safety critical errors.

\section{Conclusion}

This paper summarized operator-in-the-loop studies that were performed using the utility's qualified on-site NPP control room simulators to assess the human factors aspects and overall system performance of upgraded digital $I \& C$ systems. Having access to two different qualified on-site simulators, one which had been upgraded with the new digital $I \& C$ and another at an identical NPP located a few hours away that had not been upgraded, provided a unique opportunity to evaluate and compare operator and overall system perform- 
ance in two high-fidelity simulation environments.

The fact that this study observed no safety critical issues with the new HSIs in the upgraded simulator meets the industry-accepted standard of proof that the new I\&C system had been validated. What was unique to this research was that it also demonstrated that there were no meaningful differences in completion times for operators using the old $I \& C$ versus the new $I \& C$ that were time critical in nature. This was additional comparative evidence supporting the validation conclusion that before now had not been empirically demonstrated and provides additional assurance that commercial NPPs in the U.S. are safely operated. This assurance, using the qualified on-site simulators to validate final as-built digital I $\& C$ systems that have been modernized and deployed, directly supports DOE's strategic vision to enable the continued operation of the existing fleet of commercial NPPs.

Acknowledgments. This manuscript has been authored by Battelle Energy Alliance, LLC under Contract No. DE-AC07-05ID14517 with the U.S. Department of Energy. The United States Government retains and the publisher, by accepting the article for publication, acknowledges that the United States Government retains a nonexclusive, paid-up, irrevocable, worldwide license to publish or reproduce the published form of this manuscript, or allow others to do so, for United States Government purposes. The INL issued document number for this paper is: INL/CON-21-61472.

\section{References}

1. United States Department of Energy: Office of Nuclear Energy: Strategic Vision. Washington, D.C. (2021)

2. International Atomic Energy Agency: Modern Instrumentation and Control for Nuclear Power Plants: A Guidebook. IAEA Technical Report Series \#387, Vienna, Austria (1999)

3. Hancock, P. A., Vincenzi, D. A., Wise, J. A., \& Mouloua, M. (Eds.): Human Factors in Simulation and Training. CRC Press, Boca Raton, FL (2008)

4. Lew, R., Ulrich, T. A., Boring, R. L., Werner, S.: Applications of the Rancor Microworld Nuclear Power Plant Simulator. In: 2017 Resilience Week, pp. 143--149. IEEE Press, New York (2017)

5. American National Standards Institute/American Nuclear Society: ANSI/ANS-3.5 Nuclear Power Plant Simulators for Use in Operator Training and Examination. American Nuclear Society, La Grange Park, IL (2018)

6. United States Nuclear Regulatory Commission: Regulatory Guide 1.149 Nuclear Power Plant Simulation Facilities for Use in Operator Training, License Examinations, and Applicant Experience Requirements (Reg Guide 1.149). Washington, DC (2011) 
7. Sauro, J., Lewis, J.R.: Quantifying the User Experience: Practical Statistics for User Research. Morgan Kaufmann, Burlington (2016)

8. Hart, S.G., Staveland, L.E.: Development of NASA-TLX (Task Load Index): Results of Empirical and Theoretical Research. Adv. Psychol. 52, pp. 139--183 (1988)

9. Taylor, R.M.: Situational Awareness Rating Technique (SART): The Development of a Tool for Aircrew Systems Design. In: Situational Awareness in Aerospace Operations (AGARD-CP-478), pp. 3/1-3/17, NATO, Neuilly Sur Seine (1990)

10. Lakens, D.: Equivalence Tests: A Practical Primer for Tests, Correlations, and Meta-Analysis. Soc. Psychol. Personal. Sci. 8(4), pp. 355--362 (2017). 